\title{
O Papel da Bibliografia das Publicações Indígenas do Brasil na Reafirmação das Identidades Intelectuais Ameríndias
}

\author{
Ana Luísa Melo Ferreira \\ Université Panthéon-Sorbonne Paris 1
}

\begin{abstract}
O ensino superior brasileiro e a produção científica foram, historicamente, espaços destinados a uma elite branca privilegiada. Aos povos indígenas, bem como a mulheres e negros, foi-lhes negado, ao longo dos anos, o poder de participação e produção de um conhecimento considerado também legitimo. No entanto, uma nova corrente intelectual indígena decolonial surge para mostrar que há outras formas de saber válidas. Ao mesmo tempo em que se reafirmam enquanto indivíduos e como comunidade, eles contribuem para a difusão de uma pluralidade de ideias e interpretações de mundo. Deste modo, o principal foco deste artigo é entender qual o papel da participação indígena na produção científica acadêmica e como recentes iniciativas - tal qual a Bibliografia das Publicações Indígenas do Brasil - contribuem para o resgate de sua autoestima e a sua afirmação em um meio excludente.
\end{abstract}

Palavras-chave: indígenas, academia, ciência, metodologia, decolonialismo

\begin{abstract}
Introdução
Karú-Sakaibê é o criador da vida, dos céus e das montanhas, dos rios, dos animais e dos Munduruku. Os velhos sábios contam que Karú-Sakaibê andava pelo mundo sempre acompanhado de seu grande amigo Rairu, um jovem brincalhão, no entanto poderoso. Em uma dessas brincadeiras, Rairu formou uma figura de tatu usando folhas e gravetos, finalizando-a com um pouco de cera de resina de mel e, para que secasse, enterrou-a. $\mathrm{O}$ que Rairu não imaginava, contudo, é que sua mão ficaria colada na cauda do pequeno tatu, e, no intuito de soltá-la, ele acabou o trazendo à vida. O tatu, tão forte quanto seu dono, cavou tanto, mas tanto, que chegou ao centro da terra, arrastando consigo o pobre Rairu. Lá, ficaram chocados com o que encontraram: um povo bonito e diferente. Correram, então, para contar a Karú o que havia acontecido, e o deus decidiu que aquela gente não ficaria mais escondida ali, mas que agora habitaria a superfície. Por isso, deulhes a chuva, a mandioca, a batata, as plantas medicinais e outros alimentos, e eles se tornariam, assim, uma nação orgulhosa e guerreira. Este conto (Munduruku, 2021), bem como incontáveis outros, está no cerne da origem Munduruku.
\end{abstract}

Mitos como estes, centrais na cosmovisão indígena, são comumente classificados como estórias infanto-juvenis, nada além de um folclore ingênuo para os olhares longínquos. Isso se dá pois as formas de conhecimento indígena são invalidadas por uma supremacia branca do conhecimento. Na realidade, os arranjos modernos institucionais garantem um cânone do conhecimento à Europa que perpetua processos racistas ao naturalizar a "excepcionalidade" da europeidade (Araújo \& Maeso, 2016). Isso quer dizer que a forma como produzimos saber ainda é pautada em uma perspectiva eurocentrada, uma prática política, histórica e acadêmica na qual grupos excluídos tiveram pouco ou quase nenhum 
poder de contribuição. Logo, a maneira tradicional de se fazer conhecimento silenciou as vozes daqueles localizados às margens, como mulheres, negros e povos originários. Esta maneira, classificada como monopólio da ciência por Valadares e Silveira Júnior (2017), evidencia a falta de representatividade na produção do saber, ao passo que quem detinha os meios de conhecimento partia do pressuposto de que a experiência de homens brancos era a mesma da humanidade em geral.

Isto posto, propor-nos-emos, neste trabalho, a fazer uma crítica ao modelo acadêmico no Brasil e, ao mesmo tempo, apontar iniciativas de resistência de contrapúblicos subalternos ${ }^{1}$, mais especificamente dos povos indígenas. Estes últimos, por meio de uma coordenação orgânica, buscam reivindicar seu lugar na construção e estabelecimento de epistemologias alternativas que também sejam consideradas legítimas. Além disso, iremos examinar como os povos indígenas, no ambiente acadêmico e fora dele, buscam trazer para si a autonomia de serem produtores soberanos de conhecimento, seja ele tradicional ou não. Deste modo, a participação ativa dos povos originários na ciência se torna crucial para a superação de contradições na academia e nos métodos científicos, propondo e provocando novas metodologias que englobem e validem diferentes perspectivas. É o caso, por exemplo, da Bibliografia das Publicações Indígenas do Brasil (BPIB), organizada de forma colaborativa por diferentes intelectuais indígenas brasileiros e que será estudada a seguir.

Escolhemos este tema a partir do entendimento de que a produção que aborde o protagonismo indígena na academia ainda é limitada e não dá o devido destaque às potentes iniciativas dos povos originários. Nós acreditamos na capacidade dos povos indígenas em ocupar e revolucionar espaços outrora negados, e na importância em estarem presentes em lugares historicamente excludentes e etilizados, como é a academia. Assim, trazer a ótica de quem está na linha de frente desta reconfiguração no fazer ciência representa o nosso desejo em poder entender melhor tal fenômeno e, concomitantemente, contribuir com um olhar sensível às suas formas de agir. No entanto, a falta e o difícil acesso aos dados sobre indígenas na ciência acabam por nos limitar, parecendo-nos a melhor solução nos apoiar em uma bibliografia pré-existente e, sobretudo, nas entrevistas dos personagens principais desta narrativa. Por meio desta metodologia, buscamos usar ferramentas que permitissem centralizar as experiências ameríndias e em seguida analisálas mediante um processo horizontalizado. Conduzimos a nossa pesquisa no intuito de responder a alguns questionamentos, em particular se participação de povos indígenas na produção científica consegue, em algum grau, fomentar a descolonização da academia e de suas metodologias e de que forma iniciativas como a BPIB contribuem para uma melhora na autoestima dos pesquisadores indígenas na academia.

Para tal, nos baseamos em uma revisão da produção científica dando preferência aos estudos de pessoas indígenas, brasileiras e estrangeiras, mas também recorrendo, caso necessário, ao que já foi escrito por não-indígenas. Além disso, entrevistamos dois pesquisadores indígenas ativistas pela legitimação do conhecimento ameríndio, bem como uma das responsáveis pela criação da BPIB. Ao longo dos meses de junho e julho de 2021, conversamos com o Professor Doutor em Direito Álvaro de Azevedo Gonzaga, da etnia Guarani-Kaiowá; com Edson Krenak, da etnia Krenak, Doutor em Antropologia Cultural e possui Especialização Jurídica pela Universidade de Viena; e com Aline Franca, Mestre em Biblioteconomia e bibliotecárica coordenadora da Bibliografia das Publicações Indígenas do Brasil. Eles nos trouxeram um panorama baseados em suas vivências enquanto indígenas (no caso do professor Álvaro e de Edson Krenak), assim como

1 A definição de contrapúblicos subalternos foi explorada por Nancy Fraser (1990) em seu artigo Rethinking the Public Sphere: A Contribution to the Critique of Actually Existing Democracy. 
ativistas pela causa e dignidade dos povos indígenas, como é o caso de Aline Franca. As entrevistas foram organizadas de forma semiestruturada, com perguntas gerais e em seguida aprofundadas conforme a discussão se desenrolava, e realizada de maneira remota.

Optamos por esses três entrevistados por serem pessoas que se posicionam de forma assertiva na defesa da produção intelectual indígena. Edson Krenak, por exemplo, é ativista por uma educação descolonizadora e se articula nacional e internacionalmente a fim de repensar as literaturas e metodologias ameríndias. Álvaro de Azevedo Gonzaga, por outro lado, é professor, advogado e militante pelos direitos humanos e pelos direitos dos povos indígenas. Além de já ter escrito livros sobre o decolonialismo indígena, possui uma longa trajetória de investigação e atuação na causa indígena. Aline Franca, cujo tema de dissertação de mestrado em biblioteconomia foi A Representação Bibliográfica da Autoria Indígena no Brasil (2016), articula-se diretamente com intelectuais originários para abastecer o seu projeto, Bibliografia das Publicações Indígenas do Brasil. Dessa forma, todos detêm um vasto conhecimento empírico e epistemológico que, ao serem compartilhados, enriquecem o nosso debate e contribuem com novas interpretações críticas sobre o papel deste grupo na consolidação da sua forma de ser e saber.

\section{A invisibilidade na academia}

Devemos começar a discutir a participação de grupos marginais ${ }^{2}$ na academia - mais precisamente os povos indígenas - fazendo um recapitulativo do modelo de educação tradicional brasileiro. Neste âmbito, é essencial relembrar que o atual estágio de apagamento, contradições e incoerências é o resultado de um longo processo de exclusão sistêmica de todos aqueles que não se encontrassem na interface homem-branco-rico. Foi neste contexto, portanto, que se estabeleceu um modelo totalitário de racionalidade que ainda orienta a nossa forma de classificar o que é conhecimento e, por conseguinte, do que é e como fazer a verdadeira ciência (Piza \& Pansarelli, 2012).

A história da educação superior no Brasil é marcada por profundas desigualdades (Derossi \& Carvalho, 2021). A exclusão de grupos marginais fez parte, desde o princípio, da agenda portuguesa de impedir a autonomia intelectual em sua colônia mais próspera, monopolizando, assim, a esfera de ensino (Durham, 2003). Tal fato pode ser observado durante a criação da primeira instituição de ensino superior brasileira, em 1808, motivada pela chegada da família real portuguesa fugida da ameaça napoleônica e não pelo desejo intrínseco de suprir as necessidades educacionais nacionais (Braga \& Mazzeu, 2017).

Até então, os únicos a terem acesso às universidades eram herdeiros de família abastadas que deviam se deslocar aos centros urbanos da Metrópole, em Portugal, para estudar. Em seguida, para eles também foram destinados espaços restritos de produção de conhecimento quando a mesma já acontecia no Brasil. Deste modo, a educação esteve reservada à uma pequena parcela da população privilegiada, ressaltando seu caráter elitista, excludente e centralizador (Novaes et al., 2018). Para Garcia (2000), os déficits estruturais da educação superior brasileira ainda refletem a "hegemonia dos que se pretendiam proprietários do saber, que eram também os proprietários das terras e de

\footnotetext{
${ }^{2}$ Partiremos da noção de grupos marginalizados, ou minorias, presente no trabalho de Danner et al. (2020). Desta forma nos referimos a grupos invisibilizados, silenciados e excluídos pelo sujeito colonizador. Estes grupos são, segundo os autores, vítimas de uma menoridade moral, condição essa que apaga seus discursos e lhes nega sua maioridade política. No caso dos povos indígenas, eles viveriam numa condição de maioridade relativa, sob uma tutela tecnocrática na qual eles seriam meros objetos do Estado, mas nunca sujeitos.
} 
todas as riquezas produzidas, e que se valiam do saber para justificar seu poder" (p.68). Isto é visível, por exemplo, em dados que revelam que, nos anos 1900, cerca de $65.3 \%$ da população brasileira ainda era analfabeta (Braga \& Mazzeu, 2017).

A educação moderna, em vista disso, teve como base premissas racistas, classistas e misóginas que deixaram de fora grande porcentagem da população brasileira. A começar pela modernidade que, segundo Ballestrin (2017), é tanto uma época quanto um processo, uma ideologia e uma lógica que positivou a razão e a civilização através da violência colonial sobre outros modelos de sentir, pensar e agir (p. 522). Neste contexto, solidificouse uma forma específica de racionalidade que tem como uma das consequências a destruição de outras formas de saber (Hoffmeister et al., 2016). Ela pauta, todavia, os nossos princípios epistemológicos e regras metodológicas complexas, tornando-os por vezes inacessíveis. Nesta racionalidade, o que não é quantificável se torna irrelevante. A contínua reprodução das narrativas ocidentais, em particular da europeia, leva à formação de uma subjetividade domesticada e heteronônoma (Piza, 2018, p.113). Por outro lado, ela reduz a sua complexidade ao não considerar outras perspectivas não-imperiais, tão essenciais para a pluralidade no debate das ideias.

O desenvolvimento do capitalismo econômico, que se inicia a partir da acumulação primitiva do capital (Federici, 2004), esteve diretamente associado ao monopólio da ciência, de acordo com Valadares e Silveira Júnior (2017). Tal fato levou a imposição de supostas verdades universais - baseadas, sobretudo, em conceitos da Revolução Científica emergentes no século XVI (Gomes, 2012) - aos grupos explorados. Como consequência, culturas e saberes fora do eixo eurocêntrico foram invalidadas, tornando-se, inclusive, objetos de estudos caricatos e estereotipados vistos sob a ótica dos detentores da razão. Deste modo, o conhecimento, como o percebemos hoje, solidificou-se nos objetivos e intenções daqueles que detinham a hegemonia de poder (Monk \& García-Ramon, 1987). No contexto brasileiro, esta hegemonia esteve e está intimamente relacionada ao seu passado colonial.

Boaventura de Sousa Santos (2018), em sua obra Epistemologias do Sul, explora o epistemicídio como o fenômeno que colocou o colonialismo como uma forma de conhecimento que se autorregulava. Ele o considera, também, um dos maiores crimes contra a humanidade. Segundo o autor,

[...] o genocídio que pontuou tantas vezes a expansão europeia foi também um epistemicídio: eliminaram-se povos estranhos porque tinham formas de conhecimento estranho e eliminaram-se formas de conhecimento estranho porque eram sustentadas por práticas sociais e povos estranhos. Mas o epistemicídio foi muito mais vasto que o genocídio porque ocorreu sempre que se pretendeu subalternizar, subordinar, marginalizar, ou ilegalizar práticas e grupos sociais que podiam constituir uma ameaça à expansão capitalista ou, durante boa parte do nosso século, à expansão comunista (neste domínio tão moderna quanto a capitalista); e também porque ocorreu tanto no espaço periférico, extra-europeu e extra-norte-americano do sistema mundial, como no espaço central europeu e norte-americano, contra os trabalhadores, os índios, os negros, as mulheres e as minorias em geral (étnicas, religiosas, sexuais). (p.200)

Esta ideia é reforçada por Grosfoguel (2016), ao afirmar que a legitimidade do monopólio do conhecimento gera estruturas que produzem (e reproduzem) o racismo e o sexismo epistêmico, desqualificando a oposição feita ao projeto por sua vez patriarcal, colonial, imperial e universal que regem o sistema-mundo (p.25). bell hooks (2013), indo mais além, 
acrescenta que da teoria resultante deste modo de conhecimento é feito um uso instrumental que cria hierarquias desnecessárias de pensamentos que endossam políticas de dominação. Para ela, obras consideradas teóricas são repletas de jargões, referências obscuras e difíceis de ler (p.89) que impedem a identificação e decodificação dos que estão às margens, trazendo-lhes consequências reais e materiais.

Nancy Fraser (1990), como mencionado anteriormente, aborda o pensamento de subalternidade e de como é possível reagir a ele, especialmente enquanto grupos invisibilizados. Nele, a autora analisa as premissas habermasianas de participação democrática e ressalta a importância da presença de grupos socialmente excluídos nos espaços públicos de tomada de decisão. Na contramão ao discurso de Jürgen Habermas ${ }^{3}$, ela demonstra que levar em conta a condição periférica na qual estes segmentos da sociedade estão inseridos é um fator central do processo reivindicatório. Conforme aponta Gayatri Spivak (2010), a manutenção das estruturas que acentuam as diferenças entre grupos hegemônicos e subalternos está no fato de que, para o último, é crucial que outros falem por ele. Ser subalterno, por conseguinte, é não falar ou ter sua fala tutelada por outros. Portanto, o confronto entre contra-públicos subalternos e poder hegemônico acaba sendo uma etapa inicial de democratização, ao propiciar uma maior pluralidade de representação na esfera pública (seja ela em espaços de tomada de decisão ou de ensino, especialmente pelo seu caráter político).

Edson Krenak acredita que a universidade ainda é um local onde não há abertura para a diversidade de expressões. O que acontece, de fato, é que este modelo educacional funciona pela lógica da doutrinação, para uniformizar o pensamento dos estudantes. Trata-se, de acordo com ele, de uma academia colonizada que busca silenciar as vozes e deslegitimar as tradições indígenas.

Existe, sim, um debate teórico, mas que só interessa aos teóricos para os currículos e egos deles. [...] Não existe nenhuma contribuição política, legal, social, emancipatória para os povos indígenas na universidade. As línguas indígenas, por exemplo, são posse dos departamentos de linguística ou de antropologia, mas elas quase não têm expressão nenhuma em termos de produção de conhecimento. A língua indígena é o local de conhecimento branco, colonizador. (Krenak, comunicação pessoal, 10 de julho, 2021).

Como consequência dessa exclusão conjuntural, estudantes indígenas se sentiam e se sentem abandonados e solitários, em particular face às políticas tradicionais - e equivocadas - de "inclusão". Por outro lado, eles são confrontados cotidianamente frente aos métodos e a professores cujas práticas têm profundas raízes no racismo estrutural. "Indígenas chegavam [à sala de aula] com uma bagagem enorme de conhecimento tradicional e não conheciam equações de segundo grau. Só por isso os professores já os desqualificavam, diziam para voltar para a escola [primária]" (Krenak, comunicação pessoal, 10 de julho de 2021). O ativista ressalta, entretanto, que a própria formação de tais docentes é colonizadora, não poupando sequer professores indígenas de darem

\footnotetext{
${ }^{3}$ Orientado pela Escola de Frankfurt, Habermas parte do conceito de que há uma suposta racionalidade que deve ser aplicada durante os momentos de discussão, mas que, para isso, é preciso abandonar a nossa identidade e a nossa subjetividade. Para ele, a esfera pública é um local neutro no qual pessoas devem suspender as suas diferenças enquanto indivíduos e debater como se fossem todos iguais. Esta posição é problemática visto que não somos somente diferentes, como possuímos trajetórias diferentes que nos moldam e nos orientam. Nossas emoções, deste modo, são um motor que nos fazem lutar para sermos levado em consideração nas tomadas de decisão em uma democracia.
} 
continuidade à maneira de educar que os oprime. Para ele, falta uma formação essencialmente indígena.

Em contrapartida, a academia é um espaço de onde emergem contra-condutas que, segundo Alabarce et al. (2020), causam tensão entre projetos neoliberais que colocam o saber acadêmico constantemente em risco. É no meio acadêmico que se procura entender o mundo, a sociedade e seus fenômenos naturais ou humanos. As universidades, apesar de suas falhas, ainda se mantêm como um espaço de discussão e de busca por educação de qualidade, plural e emancipatória. De acordo com Romão (2013), o ensino superior e a sua maneira de existir estão em uma profunda crise identitária; é certo, porém, que é através deste processo que se torna possível se reinventar. Em diálogo com as obras de Paulo Freire, o autor acredita que a solução para o ensino superior está em sua própria superação institucional, curricular e científica. Para ele, o ato de superar

[...] não significa negar-se e negar a sua história, mas descobrir-se em um novo contexto, a partir da síntese de suas próprias contradições internas, o que significa encarar a superação dialética como autotransformação, como substituição do imediato pelo mediato, em suma, enquanto "mediatização", como gostava de dizer Paulo Freire (2013, p. 93).

Neste cenário, grupos socialmente esquecidos desempenham um papel central na superação, pois possuem as ferramentas para apontar equívocos e trazer novas interpretações da nossa realidade, muito mais subjetiva do que se ouse afirmar. A seguir, exploraremos como povos originários assumem para si a responsabilidade de serem também agentes ativos na busca do conhecimento, saindo do local passivo de eternos sujeitos de estudo para operarem como produtores de saber.

\section{Ciência também é coisa de indígena}

No que tange a participação de estudantes ameríndios na academia, compartilhamos a perspectiva de Smith (2021) ao assegurar que a atividade de se fazer pesquisa é transformada quando povos indígenas passam a ser os pesquisadores e não apenas os meros objetos de pesquisa. Com a sua presença nesses locais, as questões são formadas de maneiras distintas e as prioridades são repensadas (p.193). É a produção de conhecimento feito por eles e para eles e suas comunidades.

O Brasil conta, atualmente, com 494 docentes indígenas em exercício na Educação Superior, dos quais 196 são mulheres e 298 são homens. De 386.073 professores, eles representam $0.1 \%$, do total, conforme dados do Instituto Nacional de Estudos e Pesquisas Educacionais Anísio Teixeira (INPE), do Ministério da Educação ${ }^{4}$ No que tange a sua presença nas universidades, eles eram, em 2019,0.7\% dos estudantes matriculados a se autodeclarar indígenas. Contudo, apesar dos números discretos, eles mostram um cenário otimista: a presença de alunos indígenas no ensino cresce exponencialmente a cada ano (Herbetta \& Nazareno, 2020).

Os povos originários também estão na pós-graduação, tornando-se mestres e doutores na vanguarda de uma produção acadêmica feita por e para indígenas. Eles fazem parte de uma nova classe intelectual autóctone, sendo a autoria acadêmica indígena um fenômeno social em emergência (Reichert, 2019). É, destarte, uma ação política que ousa romper com

\footnotetext{
${ }^{4}$ Estes dados nos foram disponibilizados pelo Instituto Nacional de Educação, do Ministério da Educação, através da Lei de acesso à informação. Eles foram baseados no Censo de 2019 sobre o número de docentes total e indígenas das instituições de educação superior.
} 
moldes coloniais. Assim, "a autoria indígena está no fato de ter reconhecido o seu lugar de fala, independentemente da condição em que tal fala se inscreve" (Portela \& Nogueira, 2016, p.158).

As autoras ainda lembram que o ingresso de indígenas no ensino superior é um acontecimento recente (2016, p.12), que teve seu início no governo petista de Luiz Inácio Lula da Silva (2003-2010). Os anos 2000, assim sendo, foram marcados por iniciativas que buscavam maior inclusão destes povos no campo social das políticas públicas, em particular no acesso ao ensino superior. Em 2012, a aprovação da Lei 12.211/2012 conhecida como Lei de Cotas - foi uma inegável conquista e um importante avanço na democratização do ensino a segmentos historicamente excluídos (Baniwa, 2013). A ação afirmativa, sancionada pela ex-presidente Dilma Rousseff (Partido dos Trabalhadores), permitiu que o número de vagas direcionadas a povos indígenas aumentasse em $544 \%$ desde a implementação dessa lei, segundo dados do Censo da Educação Superior, do Ministério da Educação (INEP/MEC, 2018). É necessário, porém, observar a iniciativa com cautela, visto que ela é o pontapé para "pensar o enfrentamento mais pragmático das desigualdades associadas à exclusão e discriminação racial, sociocultural, econômica e étnica" (Baniwa, 2013, p.18).

Felipe Cruz, antropólogo indígena brasileiro, percebe, a partir de sua experiência, que estudantes autóctones pretendem dominar não só o conhecimento branco, mas ocupar lugares estratégicos dentro da academia como forma de romper práticas de tutela que vão na contramão do almejado protagonismo indígena (2016, p.26). Deste modo, povos originários buscam, na formação superior, uma via alternativa e legítima de participação sociopolítica para atender seus desejos e os de suas comunidades. Isso também os capacitam na gestão de seus territórios ao mesmo tempo em que lhes dão condições favoráveis para exercerem sua cidadania.

Paralelamente a Cruz (2016), Álvaro de Azevedo Gonzaga, durante entrevista, retoma o conceito de etnocídio mencionado anteriormente por Boaventura de Sousa Santos e explica as razões pelas quais presença de estudantes indígenas no ensino superior é uma estratégia para vencê-lo.

A luta etnocida [indígena versus conhecimento colonizado] é justamente essa. $\mathrm{O}$ etnocídio nada mais é do que 'eu estrangular' a sua cultura. A cultura universitária tem uma política etnocida, na qual os indígenas precisam entender o seu papel na universidade, abastecer-se de conhecimento colonizador para que possa operacionalizar, dentro dos aparelhos estatais, dentro das estratégias políticas que existem, formas de ação. No direito, por exemplo, aprender como se judicializam determinadas questões é uma delas. (Azevedo Gonzaga, comunicação pessoal, 22 de junho, 2021).

Krenak, seguindo a mesma linha de raciocínio que Azevedo Gonzaga, aponta que foi o sentimento de serem massacrados por um sistema que não os contemplava o que os permitiu reagir. "Isso deu espaço para aquilo que é bastante indígena, para a resistência. Nos deu forças para criar laços e comunidades indígenas dentro das universidades. Foi assim que nos fortalecemos" (Krenak, comunicação pessoal, 10 de julho de 2021). Este fortalecimento se deu com maior ingresso de indígenas na universidade e na ocupação de lugares considerados não-indígenas.

Nós já começamos a trilhar este caminho, ao entrar nas universidades e discutirmos, questionarmos e termos esse debate público. Alguns indígenas têm 
usado suas mídias sociais para questionar estes parâmetros. Nós estamos forçando os portões a se abrirem para nós, mas, quando entramos, não queremos entrar sozinhos. Queremos entrar como parceiros, com nossos conhecimentos e nossas tradições. Não queremos entrar para sermos formados nos padrões colonizadores. A gente quer dialogar e precisamos ter a habilidade de sentar a mesa para negociar. (Krenak, comunicação pessoal, 10 de julho de 2021).

Daniel Munduruku, em sua obra O caráter educativo do movimento indígena brasileiro (19701990), acredita que esta tomada de consciência está ligada ao processo de apoderamento, feito pelo seu povo, do mecanismo teórico ocidental. "Esta capacidade de alargar os horizontes mentais para enxergar de forma mais clara o entorno, o nacional, exigiu nova postura e redimensionamento do que era, até então, dado como verdade" (Munduruku, 2012, p.211). A organização dos povos indígenas faz parte de um momento de mudanças históricas que, impulsionadas por transformações políticas, influenciaram a forma como eles passaram a perceber a sua relação com o Estado e como eles se posicionariam face a ele. Surgiram, à vista disso, novas demandas que se converteriam em pautas de luta (Silva, Costa e Esteves, 2017).

Célia Xakriabá (2018) crê que dialogar com outras epistemologias se mostra uma tarefa desafiadora, visto que uma das necessidades é a de descolonizar conhecimentos perpassados no meio acadêmico (p.56). Segundo ela, o protagonismo de acadêmicos e anciões indígenas é crescente. Pouco a pouco eles deixam de ocupar o lugar de objetos de pesquisa para se tornarem produtores de conhecimento das suas comunidades. "Ocupar, marcar e demarcar o espaço no meio acadêmico é sem dúvida uma ferramenta de luta" (Xakriabá, p.102). A autora nos lembra que:

Apesar de ainda existir um grande desafio, a nossa presença na universidade faz diferença e tem sido muito mais que formação acadêmica, tem também nos preparado para transitar em mundos diferentes, conhecer o "novo", outras culturas, outros conhecimentos, mas com a convicção de que o que queremos mesmo é fortalecer e tornar ainda mais significativas a nossa cultura e a nossa identidade. (Xakriabá, 2018, p.57).

Baniwa (2013) reitera os princípios de comunidade mencionados por Xakriabá (2018), ao ressaltar que povos originários não visam se enquadrar em lógicas academicistas que alimentam e sustentam os processos de reprodução do capitalismo individualista. $\mathrm{Na}$ contramão da barbárie e selvageria resultantes do atual modelo econômico, eles gostariam, na realidade, de compartilhar seus saberes, valores comunitários, cosmologias, modos de ser e de viver onde o bem-estar coletivo seja a prioridade $(2013$, p.18). A grande dificuldade, portanto, está neste encontro entre civilizações que de um lado se baseiam em princípios de partilha, e a de outra, a ocidental, prepotente e autocentrada (Tamaná, 2021).

Os saberes das comunidades indígenas são apresentados através da oralidade e, apesar das extensas tentativas de aculturação coloniais que os cerceiam, eles resistem para manter seu legado. A diversidade cultural presente em seus conceitos epistemológicos é de grande valor para a sua construção acadêmica e para sua pedagogia da vida (Coimbra e Branco, 2020). Ademais, o próprio movimento indígena é considerado como uma universidade por alguns, já que possibilita a produção de um conhecimento corporificado pelo engajamento na luta. É uma instituição certamente invisibilizada, porém que valoriza a trajetória, e não só o ponto de partida ou de chegada (Xakriabá, 2018, p.57). 
A ciência indígena se mostra uma via possível e necessária para a construção de uma sociedade solidária, na qual não apenas o bem-estar humano seja levado em conta, mas toda forma de vida que existe no planeta Terra. A proteção dos conhecimentos tradicionais, além de sua aplicação, pode direcionar a humanidade para um futuro em que a natureza não seja vista como território de dominação e sim como parte essencial a cada um de nós. O modo de ser indígena deve servir para a nossa perspectiva ocidental como uma revolução em conceitos que seguem nos colocando em risco, pois ainda funciona como um meio para fins neoliberais.

Não obstante, isso perpassa pela legitimação destes saberes, pela descolonização do conhecimento. Um dos obstáculos encontrados e a ser superado pelos povos originários ao longo de suas trajetórias acadêmicas é a necessidade de aprender teorias e conceitos que não se encaixam no pensar holístico de seus povos, sendo uma agressão ao seu sistema mental (Munduruku, 2017). Quando se trata de saberes tradicionais autóctones, eles se baseiam em uma dependência dos fatos observados, em uma observação contínua e direta do que se estuda relacionada às suas origens e ancestralidade. A ciência, por outro lado, opera com modelos explicativos e pré-estabelecidos. A esta segunda se dá uma heurística maior do que ao conhecimento dos povos originários, que acaba sendo reduzido a estereótipos.

Além disso, mesmo que alguns desses estudantes indígenas se destaquem na formação acadêmica, tornem-se mestres e doutores, ainda figuram no imaginário social como "exceção à regra", tendo sua produção acadêmica pouco difundida (Portela \& Nogueira, 2016). É por isso que iniciativas como a Bibliografia das Publicações Indígenas do Brasil, a qual estudaremos a seguir, são cruciais para a divulgação da ciência indígena.

\section{A Bibliografia das Publicações Indígenas do Brasil, uma ferramenta de autoestima}

A autoestima é um elemento essencial à nossa existência, que determina como nos sentimos sobre nós mesmos. É o sentimento que valoriza nossos traços sociais, mentais e espirituais que configuram a nossa personalidade, e é um importante indicador do nível de satisfação que uma pessoa tem consigo mesma (Maggio, 2000 como citado em Solano $\&$ Salas, 2010). No contexto dos povos indígenas, ela está associada a um período de busca étnica no qual se explora a sua própria etnicidade até que ela seja internalizada. Deste modo, alcançar esta apreciação de si reflete em maiores níveis de satisfação pessoal em comparação com aqueles que não trabalharam a sua etnicidade, mostrando que a forma como os corpos indígenas se posicionam está conectada a como eles veem o seu papel no mundo.

"A coisa mais bonita que temos dentro de nós é a dignidade", disse Eliane Potiguara em 2008, em seu trabalho Identidade e voz indígena. Não importa quão maltratados ou tristes estejamos, é preciso ser resiliente. Para ela, bonito é florir, mesmo que isso aconteça em meio aos ensinamentos impostos pelo poder. É lindo poder renascer diariamente. "Um futuro digno espera os povos indígenas de todo o mundo. Foram muitas as vidas violadas, culturas, tradições, religiões, espiritualidade e línguas. A verdade está chegando à tona, mesmo que nos arranquem os dentes!" (p.79).

O processo de resgate da autoestima indígena perpassa, de um lado, por iniciativas de políticas públicas, mas ele provém sobretudo dos meios de ações independentes de empoderamento autônomo próprios às comunidades ameríndias. A fim de superar a tutela de raiz colonial, surgem novos dispositivos que transmutam a responsabilidade de expressão para si e questionam a organização social que os coloca como coadjuvantes de 
suas próprias histórias. A Bibliografia das Publicações Indígenas do Brasil, da mesma forma que iniciativas como Leia Mulheres Indígenas ${ }^{5}$, por exemplo, vem para relembrar que o conhecimento tradicional indígena pode trazer progresso à comunidade que os cerceia.

A Bibliografia das Publicações Indígenas do Brasil foi criada em 2019 por Aline Franca, Daniel Munduruku ${ }^{6}$ e Thúlio Gomes ${ }^{7}$. Trata-se de uma bibliografia colaborativa hospedada na plataforma Wikilivros que lista as publicações de diversos autores indígenas brasileiros. Sua principal intenção é de possibilitar a autores e pesquisadores, indígenas ou não indígenas, o acesso às produções ameríndias locais. A bibliografia conta com obras literárias, bem como teses e dissertações indígenas. De acordo com Aline Franca, sua fundadora, a bibliografia

[...] é um instrumento de organização de informação que, para nós que somos bibliotecários, é muito cotidiano, banal. Só que normalmente as bibliografias são temáticas e até então não existia uma bibliografia disposta a registrar essa produção bibliográfica dos escritores indígenas. A questão era resolver essa lacuna informacional que era minha, mas também era dos escritores indígenas, para que a gente tivesse esse repertório e as pessoas pudessem acessar e ver que existe literatura indígena - e ela não é pequena, não. (Franca, comunicação pessoal, 06 de julho de 2021).

A iniciativa surgiu de um sentimento de indiferença com a produção indígena no meio bibliotecário, percebido por ela durante um estágio na graduação.

No momento em que eu escutei uma pessoa falar "isso é coisa de índio, ninguém vai procurar, não serve para nada, pode deixar em uma caixa ali no canto" e eu falei "não, isso não é justo", ali eu já tinha muito claro para mim, mesmo que eu não soubesse, qual era o meu posicionamento, de qual lado eu estava. (Franca, comunicação pessoal, 06 de julho de 2021).

A bibliotecária, assim, decidiu colocar em prática uma ferramenta que funcionaria para listar documentos que demonstrassem que existe uma produção literária e científica indígena. Franca afirma que houve uma excelente receptividade por parte destes autores e pesquisadores,

[...] porque veio ao encontro da necessidade que já existia. Eu comecei a fazer o levantamento ao mesmo tempo em que entrava em contato com alguns escritores [indígenas], a apresentar essa proposta a eles e pedir que eles me dissessem se faltava alguma de suas obras. A ideia era elaborar uma ferramenta que fosse fácil, simples e útil, mas que desde a sua gênese fosse coletiva. Assim como as formas

\footnotetext{
${ }^{5} \mathrm{O}$ projeto Leia Mulheres Indígenas foi criado por intelectuais e ativistas indígenas no intuito de difundir e valorizar a produção intelectual de mulheres indígenas brasileiras.

${ }^{6}$ Daniel Munduruku, nascido em Belém do Pará, em 1964, é um professor, ativista e escritor indígena brasileiro pertencente à etnia Munduruku. Possui graduação em história, filosofia e psicologia pelo Centro Universitário Salesiano de São Paulo (UNISAL), bem como mestrado e doutorado em educação pela Universidade de São Paulo (USP) e pós-doutorado em linguística pela Universidade Federal de São Carlos (Ufscar). Seus livros já receberam diversos prêmios literários nacionais e internacionais, entre eles o Prêmio Jabuti e o Prêmio Madanjeet Singh para a Promoção da Tolerância e da Não Violência, da Unesco.

7 Thúlio Pereira Dias Gomes, um dos fundadores da BPIB, é bibliotecário-documentalista da Biblioteca Universitária de Campos dos Goytacazes (BUCG), órgão pertencente à Universidade Federal Fluminense (UFF). É graduado em biblioteconomia e gestão de unidades de informação pela Universidade Federal do Rio de Janeiro (UFRJ). Possui mestrado em ciência da informação pela da Universidade Federal do Rio de Janeiro (UFRJ) em parceria com o Instituto Brasileiro de Informação em Ciência e Tecnologia (IBICT), e doutorado em ciência da informação pela Universidade de São Paulo (USP).
} 
de ver o mundo dos povos indígenas passa por essa percepção da coletividade, eu queria que a iniciativa tivesse esse perfil. (Franca, comunicação pessoal, 06 de julho de 2021).

Aline, durante a entrevista, usa a metáfora de "colocar pedras preciosas à mostra", algo que ela considera ter conseguido. Trata-se, portanto, de coletar e expor tais pedras em um lugar em que elas precisam estar para serem vistas, para trazê-las para um outro patamar. É assim que elas poderão ser vistas e as pessoas saberão que elas existem. É, logo, um fenômeno de reafirmar e validar tais produções e seus devidos tipos de conhecimento. Isso é valioso, posto que, de acordo com de Oliveira (2006), povos ameríndios ainda atribuem ao outro um alto significado a como eles se reconhecem. A luta pelo reconhecimento identitário é, porém, uma luta política que busca a autoafirmação e que vai ao encontro de uma dignidade tão menosprezada no passado (p.55).

Eu não percebia a dimensão que a bibliografia tomou. Conforme eu comecei a movimentar alguns pesquisadores para saber se eles me indicavam outros pesquisadores indígenas, eu senti que muitos deles ficavam felizes em contribuir. A bibliografia se tornou algo como se fosse um hall dos pesquisadores indígenas. Eu acredito que, de alguma forma, houve esse tipo de impacto. Não foi proposital, porque a ideia não era criar um hall dos doutores e mestres indígenas, mas a ideia era justamente agir dando visibilidade para a produção acadêmica desses pesquisadores, que são muitas vezes invisibilizados dentro do próprio universo acadêmico. Eles estão dentro da academia, produzindo conhecimento. Não que o conhecimento tradicional não seja válido, mas eles romperam essa barreira da vivência em um meio não-indígena, se submeteram ao universo acadêmico para produzir conhecimento que também é validado pela academia e eles passam a transitar nos dois campos de conhecimento, no acadêmico e tradicional. (Franca, comunicação pessoal, 06 de julho de 2021).

Para Bergamaschi (2014), essa transição poderia ser descrita como interciência. Seria, em outras palavras, o diálogo entre diferentes ciências, levando-se em conta as distintas formas de interação entre ciência moderna e o conhecimento tradicional. Nesse contexto, tais estudantes estariam a cargo de "indianizar" espaços acadêmicos com seus modos de fazer pesquisa e de produzir conhecimento (p.27). Ainda que soe utópico colocar em contato duas culturas e concepções de aprendizagem antagônicas, este movimento de ocupação de ferramentas acadêmicas vem para rever, criticar, reformular e, quem sabe, subverter o modelo pedagógico formal, resultando em um universo mais diversificado e fraterno. A BPIB, nesta perspectiva, cumpre a sua missão de coletivizar os saberes.

O professor Álvaro de Azevedo Gonzaga, um de nossos entrevistados, iniciou a nossa discussão ressaltando o papel do reconhecimento étnico para a consolidação de sua autoestima universitária, até então em conflito pelas incertezas de seu passado ameríndio. Para falar sobre o futuro dos povos indígenas, ele precisou passar pelo processo de compreensão de sua ancestralidade. Assim, a sua história de autoidentificação e a busca pela sua ancestralidade indígena começam durante seus estudos na Pontifícia Universidade Católica de São Paulo (PUC-SP) ao se deparar com outros estudantes indígenas, mais especificamente o Grupo Pindorama ${ }^{8}$. Nesse período, foi capaz de se reconhecer enquanto membro do povo Guarani-Kaiowá, de reconhecer seus semelhantes e a sua atuação na construção de novos saberes. Esse processo foi o que Bergamaschi (2014) definiu como um "caminho de volta para casa".

${ }^{8}$ O projeto Pindorama foi idealizado por professores da PUC-SP, cujo objetivo é receber estudantes indígenas e de fortalecer as suas identidades. 
Atualmente, Álvaro é orientado por uma força decolonial que ressignifica a participação do indígena na ciência. Conforme Backes (2018), isto ocorre dado que povos ameríndios abraçam seus conhecimentos mesmo que a cultura ocidental e sua epistemologia hegemônica teimem em desqualificá-los. Logo, indígenas desafiam constantemente a matriz colonial e constroem pedagogias decoloniais (p.55). Segundo ele, no entanto, além de conhecer os instrumentos coloniais de educação, faz-se urgente impor-se em todas as esferas públicas, sejam elas as ruas, as instituições ou as redes sociais. Afinal,

[...] se não ocuparmos esses espaços, que força de resistência vamos oferecer? Se a gente desiste, pela dificuldade ou porque não ocuparemos o espaço ostentado, a gente entregou mesmo. O capital venceu. Estamos passando por um momento normaticida ${ }^{9}$ extremo, em que a luta, a resistência e todos os instrumentos que forem possíveis, e vozes que nos forem dadas, a gente tem que usar. (Azevedo Gonzaga, comunicação pessoal, 22 de junho de 2021).

Azevedo Gonzaga afirma que é fundamental organizar uma forma de resistência que se apodere dos mecanismos operacionais colonizadores e opressores, cujas técnicas foram, ao longo de séculos, aplicadas contra eles. Durante a nossa conversa, ele fez um paralelo com a famosa frase de Paulo Freire, que acredita que o sonho do oprimido é virar o opressor. Azevedo Gonzaga crê que esse não seria o caso dos povos ameríndios, visto que existe uma dimensão hierárquica, uma dimensão de respeito ancestral que não permite que se seduzam pelo modelo colonizador. Esta mesma perspectiva é vista no trabalho Intelectuais Indigenas, interculturalidade e educação, de Bergamaschi (2014), ao afirmar que os emergentes intelectuais indígenas possuem um forte compromisso com seu grupo social e com as lutas de seus povos.

As universidades, para os grupos ameríndios, podem ser aliadas na busca pelo empoderamento coletivo. É um aparato de afirmação, de fortalecimento de seus saberes ancestrais e de sua capacidade de negociação e intervenção no processo de criação de políticas públicas. É, outrossim, um instrumento para reforçar suas identidades, culturas e etnias. Estar na academia lhes dá uma nova força social, política e epistemológica. Propostas como a Bibliografia das Publicações Indígenas do Brasil conectam a formação acadêmica com as tradições dos povos ameríndios e trazem esperança àqueles que buscam reconhecimento em suas práticas. Ela pauta caminhos interculturais entre indígenas e não-indígenas, traz para a arena pública nomes até então apagados e democratiza o acesso a um conhecimento constantemente invalidado. É um compromisso com a justiça social - tão banalizada no Brasil de hoje.

\section{Conclusão}

Nós, enquanto pesquisadores, temos a delicada missão de produzir uma ciência emancipatória e também o compromisso moral de fazê-la de forma crítica. É por meio da produção científica que legitimamos discursos racializados que podem - ou não - serem usados contra nós. É preciso, portanto, lembrar-nos que eles não são inocentes, e que por trás de qualquer posicionamento há uma intenção, seja ela hegemônica ou libertadora. No que tange a produção acadêmica atual, fortemente estruturada em pilares racistas, sexistas e colonizadores, faz-se mais que necessário que nos engajemos, de maneira coletiva, para transformá-la. E é o que os povos ameríndios no Brasil, na contramão de

\footnotetext{
${ }^{9}$ Normaticídio, pela perspectiva de Álvaro de Azevedo Gonzaga, é a aplicação de normas que subtraem direitos de pessoas vulneráveis.
} 
uma onda conservadora que busca destruir toda a forma de conhecimento libertador, fazem a cada dia.

Os povos indígenas possuem a impressionante capacidade de serem fiéis a quem são e ao que acreditam, revelando ter um traço de humanidade que nos parece perdido em meio ao caos e à autodestruição ocidental. Na cosmovisão dos povos originários, valores como como a proteção à natureza, a valorização das suas histórias, de suas vivências e de suas vidas em comunidade atuam como baluarte de sua própria existência. Para eles, somos todos "nós". Portanto, o respeito pela vida, pelos seus ancestrais e pela sua história devem nos servir como uma alternativa legítima de se fazer ciência. Ainda que tenhamos internalizado, através de uma socialização cruel e unilateral, que certas características não servem a certos grupos de pessoas, há uma forte contracorrente que nos mostra que é possível. Mulheres ocupam, cada vez mais, espaços considerados outrora masculinos. Pessoas negras mostram que, hoje, não há mais lugar para o racismo. E indígenas se organizam para mostrar que existem outras formas de ver o mundo e que elas são tão válidas quanto todas as outras. Eles percorreram um longo percurso para chegarem aonde estão e daqui eles não sairão mais.

Ana Luísa Melo Ferreira é mestranda em Ciências Políticas, com foco em Comunicação política e institucional, na Université Panthéon-Sorbonne (Paris 1). Sua pesquisa é centrada nos ativismos de povos indígenas na América Latina, em particular na organização política de mulheres indígenas latino-americanas. 


\section{Referências Bibliográficas}

Alabarce, M. C., Hernández, N. M., \& Arce, G. M. (2020). La Academia como trinchera. Temas y Debates, 40(1) 69-77. https: / / doi.org/10.35305/ tyd.v0i0.484.

Araújo, M., \& Rodríguez M., S. (2016). Os contornos do eurocentrismo: raça, história e textos politicos. Almedina.

Backes, J. L. (2018). A construção de pedagogias decoloniais nos currículos das escolas indígenas. EccoS-Revista Científica, (45), 41-58.

https: / / doi.org/10.5585/ eccos.n45.8290.

Ballestrin, L. (2017). "Modernidade/colonialidade sem "imperialidade"? O elo perdido do giro decolonial". Dados Revista de Ciências Sociais, 60(2), p. 505-540.

Baniwa, G. (2013). Lei das Cotas e os povos indígenas: Mais um desafio para a diversidade. Cadernos de Pensamento Critico Latino-Americano, 34, 18-21. http: / / flacso.redelivre.org.br/ files / 2014/12 / XXXVcadernopensamentocritico.p df.

Bergamaschi, M. A. (2014). Intelectuais indígenas, interculturalidade e educação. Tellus, 14(26), 11-29. https: / / www.tellus.ucdb.br/tellus/article/view/297/315.

Braga, A. C., \& Mazzeu, F. J. C. (2017). O analfabetismo no Brasil: lições da história. Revista on line de Política e Gestão Educacional, (21) 24-46. https: / / doi.org/10.22633/ rpge.v21.n1.2017.9986.

Coimbra, A. C. G., \& Branco, M. L. (2020). Educação escolar indígena e saberes tradicionais: a percepção dos professores Pipipã de Kambixuru. Archivos Analíticos de Politicas Educativas. Education Policy Analysis Archives, 28(1), 174.

Correa, C. N., \& Xakriabá, C. (2018). O barro, o genipapo e o giz no fazer epistemológico de autoria xakriabá: reativação da memória por uma educação territorializada. Dissertação de Mestrado, Universidade de Brasília. https: / / repositorio.unb.br/handle/10482/34103.

Cruz, F. (2018). Entre la academia y la aldea. Algunas reflexiones sobre la formación de indígenas antropólogos en Brasil. In Anales de Antropología. 52(1), 25-33.

Da Silva, A. O., Costa, J. D. S. A., \& Esteves, V. S. (2017). A organização política das mulheres indígenas do Amapá. Anais do I Encontro de Discentes de História da UNIFAP.

Gomes, F. D. (2012). As Epistemologias do sul de Boaventura de Sousa Santos: por um resgate do sul global. Páginas de Filosofia, 4(2), 39-54.

Derossi, C. C., \& Carvalho, T. C. (2021). Sob os signos da exclusão e do elitismo: diferentes perspectivas sobre a educação e os processos de desigualdade no Brasil. Pensar Acadêmico, 19(2), 307-328. https: / / doi.org/10.21576/pa.2021v19i2.2021.

Durham, E. R. (2003). O ensino superior no Brasil: público e privado. Núcleo de Pesquisa sobre Ensino. Superior. Universidade de São Paulo. 
Federici, S. (2004). Caliban and the Witch. Autonomedia.

Fraser, N. (1990). Rethinking the public sphere: a contribution to the critique of existing democracy. Social Text, (25/26), 56-80. 10.2307/466240.

Garcia, R. (2000). O papel social da Universidade e sua repercussão na formação de professores. movimento-revista de educação, (02). https: / / doi.org/10.22409/mov.v0i02.68.

Grosfoguel, R. (2016). A estrutura do conhecimento nas universidades ocidentalizadas: racismo/sexismo epistêmico e os quatro genocídios/epistemicídios do longo século XVI. Sociedade e Estado, 31, 25-49. https: / / doi.org/10.1590/S0102-69922016000100003.

Herbetta, A. F., \& Nazareno, E. (2020). Sofrimento acadêmico e violência epistêmica: considerações iniciais sobre dores vividas em trajetórias acadêmicas indígenas. Tellus. https: / / doi.org/10.20435/ tellus.v20i41.640.

Hoffmeister, G. P., de Chelotti, J. D., \& de Araujo, L. E. B. (2018). A monocultura da mente e o etnocídio na bacia do Xingu: pela defesa de uma ecologia de saberes. Revista InterAção, 9(1), 71-97.

hooks, b. (2013). Ensinando a transgredir: A educação como prática da liberdade. São Paulo: WMF Martins Fontes.

Instituto Nacional de Estudos e Pesquisas Educacionais Anísio Teixeira/Ministério da Educação (2018). Censo da Educação Superior 2017. Divulgação dos principais resultados. Brasília: MEC

Monk, J., \& Ramón, M. D. G. (1987). Geografía feminista: una perspectiva internacional. Documents d'anàlisi geogràfica, (10), 147-157.

Munduruku, D. (2012). O caráter educativo do movimento indígena brasileiro (19701990). Paulinas.

Munduruku, D. (2017). Mundurukando II: Roda de conversa com educadores. Lorena: UK'A Editorial.

Munduruku, D. (2021). Contos indigenas brasileiros. Global Editora.

Novaes, M. A. B. D., Medeiros, J. L. D., \& Silva, A. M. O. (2018). O acesso à educação superior no Brasil (1500-1996). Revista Eletrônica Arma da Crítica, 88-105. http: / / www.repositorio.ufc.br/handle/ riufc/39682.

Oliveira, R. C. (2006). Caminhos da identidade: Ensaios sobre etnicidade e Multiculturalismo. Editora Unesp.

Piza, S. (2018). Pensar desde a América Latina: em defesa das epistemologias do Sul. PAULUS: Revista de Comunicação da FAPCOM, 2(3), ág-111. 
Piza, S. O., \& Pansarelli, D. (2012). Sobre a descolonização do conhecimento: A invenção de outras epistemologias. Estudos de Religião, 26(43), 25-35. https: / / doi.org/10.15603/2176-1078/er.v26n43p25-35.

Potiguara, E. (2008). Identidade e voz indígenas. Revista Filosofia Capital-ISSN 1982$6613,2(5), 72-85$.

Portela, C. A., \& Nogueira, M. C. R. (2016). Sobre indigenismo e autoria indígena no Brasil: novas epistemologias na contemporaneidade. História Unisinos, 20(2), 154162. http: / / dx.doi.org/10.4013/ htu.2016.202.04.

Reichert, I. C. (2019). Prospecções: doutores indígenas e a autoria acadêmica indígena no Brasil contemporâneo. Tellus, 38, 17-48. https: / / doi.org/10.20435/tellus.v19i38.550.

Romão, J. E. (2013). Paulo Freire e a universidade. Revista Lusófona de Educação, 24, 89105. https: / / core.ac.uk/download/pdf/270167958.pdf.

Santos, B. D. S. (2018). Construindo as Epistemologias do Sul: Para Um Pensamento Alternativo De Alternativas. CLACSO.

Smith, L. T. (2021). Decolonizing Methodologies: Research and Indigenous Peoples. Zed Books Ltd.

Solano, M. R., \& Salas, M. M. (2010). Autoestima en jóvenes indígenas: Borucas y Terrabas. Revista de ciencias sociales, 126-127. https: / / doi.org/10.15517/ rcs.v0i126-127.8786.

Spivak, G. C. (2010). Pode o subalterno falar? Editora UFMG.

Tamaná, L. M., \& Nascimento, r. (2021). Arte plumaria Munduruku na aldeia Nova Munduruku. Revista de comunicação científica, 8(1), 66-81.

Tavares, M. L., Valadares, J. M., \& Silveira J., C. (2017). O currículo da área de ciências e a construção de uma pedagogia intercultural: a formação de educadores indígenas na Universidade Federal de Minas Gerais (UFMG)/The science area curriculum and the construction of an intercultural pedagogy: the formation of indigineous educators... Cadernos CIMEAC, 7(1), 160-183. http: / / seer.uftm.edu.br/ revistaeletronica/index.php/cimeac/article/view/ 2172

Valadares, J. M., \& da Silveira J., C. (2020). Interculturalidade e ensino de ciências: O cotidiano de uma sala de aula. Archivos Analíticos de Políticas Educativas= Education Policy Analysis Archives, 28(1), 165. 